\title{
La République universelle des francs-maçons. De Newton à Metternich
}

\section{Annie Crépin}

\section{CpenEdition \\ Journals}

Édition électronique

URL : https://journals.openedition.org/ahrf/1013

DOI : 10.4000/ahrf.1013

ISSN : $1952-403 X$

Éditeur :

Armand Colin, Société des études robespierristes

Édition imprimée

Date de publication : 1 décembre 2000

Pagination : 166-168

ISSN : 0003-4436

Référence électronique

Annie Crépin, «La République universelle des francs-maçons. De Newton à Metternich ", Annales historiques de la Révolution française [En ligne], 322 I octobre-décembre 2000, mis en ligne le 27 avril 2006, consulté le 23 avril 2022. URL : http://journals.openedition.org/ahrf/1013 ; DOI : https://doi.org/ 10.4000/ahrf.1013

Ce document a été généré automatiquement le 23 avril 2022.

Tous droits réservés 


\title{
La République universelle des francs-maçons. De Newton à Metternich
}

\author{
Annie Crépin
}

\section{RÉFÉRENCE}

Pierre-Yves Beaurepaire, La République universelle des francs-maçons. De Newton à

Metternich, Rennes, éditions Ouest-France, 1999, col. « De mémoire d'homme :

l'histoire ", $202 \mathrm{p}$.

1 Pierre-Yves Beaurepaire, dont les lecteurs des A.H.R.F ont pu prendre connaissance des précédents ouvrages dans le $\mathrm{n}^{\circ} 317$, poursuit son œuvre novatrice sur la franc-maçonnerie, par ce livre dont le style chaleureux et la démarche pleine d'empathie à l'égard des réalités qu'il analyse, n'excluent pas la lucidité et remettent en cause bien des idées communément admises y compris par les francs-maçons eux-mêmes.

D'emblée, l'auteur, avec une grande finesse, distingue dans un avant-propos la société à secrets qu'est la franc-maçonnerie de la société secrète avec laquelle on l'a trop souvent confondue, créant chez ceux qui ne lui appartenaient pas une véritable «fascination-répulsion » qui leur firent confondre les mythes et les réalités. Un peu plus loin, l'historien consacre des pages éclairantes à sa démarche, approche renouvelée des sources traditionnelles de l'histoire maçonnique dont il a lui-même contribué à montrer la richesse pour qui sait les lire sans se limiter à un seul angle de vue: archives particulières des frères, correspondances, journaux. Il veut inciter la communauté des chercheurs à jeter les bases d'une stratégie collective d'exploration en réseaux «du fait maçonnique » qui est, selon lui, un «fait social total » relevant de l'histoire politique, sociale, culturelle et de l'histoire des représentations. En effet, ce livre est consacré à l'utopie que les francs-maçons élaborèrent dès leur fondation et qui 
fut leur raison d'être, le « rêve » d'une communication heureuse, pacifiée et immédiate entre les hommes dont Pierre-Yves Beaurepaire ne manque pas de montrer les résonances actuelles à l'heure d'Internet. Cette utopie se déclina chez les francs-maçons du xvIII ${ }^{\mathrm{e}}$ siècle selon plusieurs modes, de la cité chrétienne œcuménique à la République universelle, dans laquelle certains voulurent voir les préludes de la Révolution française. En fait, c'est la Révolution qui, en retour, ébranla les fondements de l'utopie. L'auteur suit les avatars du rêve maçonnique lors de la période charnière située entre les événements de 1789 et le surgissement des premiers mouvements libéraux et nationaux au commencement du xix ${ }^{\mathrm{e}}$ siècle, lorsque d'aucuns - amis ou ennemis de la franc-maçonnerie - souhaitèrent - ou redoutèrent - que le cosmopolitisme mondain ne se transformât en universalisme militant.

3 Pour étudier le mythe, les réalités dans lesquelles il s'incarna et l'écart qui exista entre les secondes et le premier, Pierre-Yves Beaurepaire propose au lecteur « un voyage en utopie » ou, plutôt, la découverte en quatre chapitres d'un triple horizon. Celui de la mémoire tout d'abord, car il n'est pas d'utopie sans création ou recréation « d'un récit des origines» à la vertu fondatrice, puis celui de l'espace, du microcosme que représente une loge maçonnique à l'univers dans lequel les frères rêvent de substituer leur ordre au chaos, enfin celui du temps historique qui confronte le projet franc-maçon aux Lumières radicales et aux courants d'émancipation politique des peuples et des nations.

4 Le premier chapitre illustre la méthode de l'auteur qui veut lier intrinsèquement histoire des représentations et histoire de la sociabilité, en dévoilant les buts des francs-maçons britanniques dans leur tentative de retour vers le passé. Dans les premières décennies du XvIII ${ }^{e}$ siècle, un ordre naît qui affiche sa différence irréductible avec le monde profane tout en revendiquant sa reconnaissance par les élites: la sociabilité nouvelle qu'induit cette création trouve sa légitimité dans une quête des origines qui est quête d'identité. En assignant à ses membres, dont il n'est pas sans intérêt de noter que la plupart, tel Newton, étaient en même temps des " antiquaires " de la Royal Society, le soin d'élaborer une histoire largement reconstruite qui faisait remonter la franc-maconnerie à la Genèse et montrait que les souverains, notamment ceux qui régnaient sur l'Angleterre depuis 1714, avaient soutenu la maçonnerie, la Grande Loge de Londres put en appeler à sa reconnaissance par l'État puis ensuite espérer être le substitut d'une religion d'État.

Ce faisant, se produisit une protestantisation qui fut en même temps une acculturation (par un processus que la franc-maçonnerie française accomplit, elle, par le gallicanisme puis par la laïcisation). Avec une rare pénétration, Pierre-Yves Beaurepaire nous en donne à voir toutes les nuances et les limites qui étaient ainsi posées au projet des francs-maçons. Le latidunarisme, qui imprègne les constitutions de 1723 et qui était aussi celui de la Royal Society, n'est pas "l'indifférence à la différence religieuse ", comme le montrent les réserves de Newton à l'égard du catholicisme, et aboutit à prôner une religion universelle qui s'identifie au christianisme. La République universelle des francs-maçons ne se dégage pas encore des utopies chrétiennes visant à recréer la concorde entre les chrétiens, la franc-maçonnerie britannique oscille à l'égard des «autres » entre une semi-neutralité et la tolérance, au sens restrictif du terme.

6 Dans les deux chapitres suivants, l'auteur montre comment cette république universelle tente de s'incarner dans une sociabilité qui, empruntant à des formes 
traditionnelles et parfois les renouvelant au point d'être confondue avec elles, n'en est pas moins novatrice. À condition de ne pas oublier que cette sociabilité franc-maçonne est plus unanimiste que démocratique. Une fois de plus, l'ouvrage ne cache pas les limites des réalisations de la franc-maçonnerie, placées sous le signe de l'égalité proclamée et de l'inégalité vécue. Ou plutôt l'égalité et la traternité réelles qui ont cimenté les rapports entre les maçons n'ont pu exister que parce qu'au préalable un recrutement sélectif permettait de faire de la loge le «temple de l'entre-soi », où, au demeurant, l'égalité ne s'établissait que pour un temps restreint, différent du temps " profane ». En analysant la genèse d'un " atelier » et en se livrant à une typologie des loges, l'historien prouve précisément que la plasticité de cette "sociabilité-caméléon ", qui fit aussi le succès de la franc-maçonnerie, la conduisit à s'adapter parfaitement à son environnement social, culturel, politique et par conséquent à en accepter les bornes sans vouloir le bouleverser. Elle s'épanouit dans les interstices de la société d'ordres, en transcendant ses cloisons sans les abattre.

On ne saurait nier cependant la sincérité des francs-maçons qui les poussa à multiplier les loges dans l'espace mondial, fussent-elles seulement les cellules de «l'entre-soi » fraternel qui admettait avec difficulté ou excluait juifs, musulmans, Métis et Noirs. La République universelle des françs-maçons entretint des rapports étroits, souvent de synergie, parfois de rivalité, avec les autres utopies planétaires qui fleurissaient au même moment, la République des Lettres, celle des sciences désirée par Condorcet, la République du commerce d'Adam Smith et aussi avec leurs incarnations ou leurs ébauches, le refuge huguenot, les réseaux du négoce international. Elle prit corps avec des réalisations telles que la correspondance, le certificat maçonnique, passeport avant la lettre, la tentative de définition d'un droit et d'une citoyenneté maçonniques où l'on perçoit déjà l'opposition entre une conception internationale et une approche universelle des principes d'organisation de l'humanité, qui sera un des grands débats d'après... 1945. De toutes façons, la franc-maçonnerie assura au XvIII ${ }^{\mathrm{e}}$ siècle un maillage de l'espace européen sans équivalent: la seule institution qui pourrait lui être comparée est l'Église catholique.

8 Le dernier chapitre montre comment la franc-maçonnerie est prise en étau entre l'Ancien Régime et la Révolution, son cosmopolitisme étant perçu de façon négative tant par les jacobins que par la Sainte Alliance à moins qu'ils ne cherchent à capter l'héritage au risque de le fausser. La République universelled'Anacharsis Cloots et l'Europe mystique et chrétienne de Mme de Krudener n'ont que peu à voir, en effet, avec celles des francs-maçons. Mais, en même temps, la franc-maçonnerie semble se politiser et favoriser l'éveil des nationalités en fournissant à leurs dirigeants un cadre privilégié où ils pouvaient articuler leur dessein national avec le projet universaliste d'une confédération des amis de la Liberté. Avec un remarquable sens des nuances, l'auteur étudie les ressemblances apparentes et les différences réelles entre les loges et les sociétés secrètes qui véhiculent les Lumières radicales et accueillent les jacobins européens, les carbonari puis les champions de l'émancipation nationale en Europe et en Amérique latine, bien qu'il y ait des passages entre elles grâce à leurs formes d'organisation et surtout à cause d'une minorité d'hommes qui furent-aussi- des francs-maçons libéraux. Il est incontestable cependant que, globalement, la franc-maçonnerie entre à son tour dans le champ du politique et abandonne le dogme de la non-intervention. La laïcisation de la bienfaisance maçonnique et sa mutation en 
philanthropie entraînent un engagement croissant des maçons dans la cité et leur volonté de transformer l'économie, la société, l'État.

9 Un glossaire et un index complètent utilement la lecture de cet ouvrage, nouvelle « pierre » apportée à «l'Art royal » par Pierre-Yves Beaurepaire. 